\title{
Defecography in normal volunteers: results and implications
}

\author{
P J SHORVON, S MCHUGH, N E DIAMANT, S SOMERS, \\ AND G W STEVENSON \\ From the Department of Radiology, McMaster University Medical Center, Hamilton, Ontario, Canada, and \\ Division of Gastroenterology, Department of Medicine, Toronto Western Hospital, Toronto, Ontario, Canada
}

SUMmary Forty seven healthy young volunteers underwent defecographic examination to determine the range of normal findings. Normality was shown to encompass radiological features often considered pathological. These features included broad ranges of anorectal angle and pelvic floor descent which overlap with reported pathological states. Furthermore, the formation of rectocoeles during defecation was a very common finding in women. Finally, a subgroup of the volunteers had marginal anorectal function. The marginal anorectal function and certain radiological findings such as rectocoeles or intussusceptions may predispose to later problems, or contribute to clinical problems when combined with other factors such as dietary fibre deficiency. The radiological findings raise a number of questions with respect to different aspects of the functioning of the continence and defecation mechanisms.

There has recently been increased interest in the investigation of problems of defecation and pelvic floor dysfunction using defecography (evacuation proctography). This procedure was first described by Burhenne in 1964' and although followed by a flurry of initial interest ${ }^{-1}$ has not been widely used until recently. The reports of Mahieu et al and Ekberg et al which have revived interest in the procedure, included descriptions of various radiographic abnormalities. ${ }^{-7}$ These authors' interpretations of abnormal findings, however, are questionable because of the absence of suitable control subjects to define the state of 'normality'.

This present study was carried out to determine the range of defecographic findings encountered in healthy young volunteer subjects who were not otherwise preselected. A further aim was to examine the findings according to current understanding of the continence and defecation mechanisms; in particular, the role and interaction between anal sphincter, puborectalis and/or levator muscles, and pelvic floor movement.

Address for correspondence: Dr P J Shorvon. Department of Radiology. Central Middlesex Hospital. London NW10.

Accepted for publication 28 September 1989
Methods

SUBJECTS

Ethical approval for this study was obtained from the ethics and human experimentation committees of both McMaster University and the University of Toronto in April, 1986.

Volunteers were recruited from the student population of the University of Toronto through advertisement at the Student Placement Offices. The recruiting advertisements explained only that the study was gastroenterological in nature and respondents were fully briefed when they applied. The respondents were excluded from the study if older than 35 years of age or there was a history of faecal incontinence, difficulties in defecation or past history of anorectal surgery. Forty eight subjects completed the study (23 women, 21 (1.6) (SD) yr; 25 men, 26 $(4 \cdot 8) \mathrm{yr})$. All the women were nulliparous.

All subjects completed detailed questionnaires related to gastrointestinal and somatic symptoms, health habits and beliefs, affective status, and cognitive function. These details are not reported in this paper except as relates to the subjective report of bowel function. 
DEFECOGRAPHY PROCEDURE

The technique was based upon that described by Mahieu et al. ${ }^{5 n}$ First. with the subject in the left lateral position, liquid barium $(30 \mathrm{cc})$ was inserted to coat the rectal mucosa. Then, through a disposable enema tip and with a modified caulking gun, a thick barium paste made from barium powder and potato starch according to the recipe of Mahieu et al, ${ }^{\circ}$ was introduced into the rectum until the subject reported a sensation of rectal fullness but avoiding a feeling of urgency. A volume of $80-200 \mathrm{ml}$ was inserted but some of this could be seen to have refluxed into the sigmoid colon on fluoroscopy and therefore did not represent an accurate intrarectal volume. The external anal opening was outlined by smearing it with barium impregnated petroleum jelly. A contrast soaked tampon was inserted by the women to define the position of the posterior vaginal wall. The subject was then placed in the sitting position on a specially constructed commode and examined by remote control fluoroscopy. ${ }^{x}$ Video recording was performed during a number of manocuvres: resting state; voluntary and maximal contraction of the sphincter and pelvic floor muscles ('squeeze'); straining without defecating ('strain'); coughing: and finally, during defecation. Four $105 \mathrm{~mm}$ spot films were taken, one each in the resting position; during 'squeeze'; during 'strain'; and during the final stages of defecation. Towards the end of the study the 'strain' film was omitted. A midline radiopaque centimetre ruler was included in the defecography commode" for visualisation on the films and allowed for absolute measurements of midline structures unaffected by radiographic factors.

\section{RADIATION DOSE}

Before the initiation of this study, radiation measurements using thermoluminescent dosimetry were taken during defecography in 10 patients. From these, a somatic does index and a gonadal dose were calculated by the Department of Medical Physics on the basis of volunteers receiving one minute of fluoroscopy, and four $105 \mathrm{~mm}$ spot films. The calculated doses were included in the consent together with a more familiar comparative indication of risk. These exposures were felt to constitute a maximum dose as less than one minute of fluroscopy was used in nearly all cases. The estimated radiation exposure was: somatic dose index (mrad): men 210, women 100; gonadal dose index (mrad): men 40, women 90.

\section{RADIOGRAPHIC ANAI.YSIS}

The $105 \mathrm{~mm}$ films and video recordings were analysed by all the authors. The measurements were taken by the radiologists (GWS, PS) from the 105

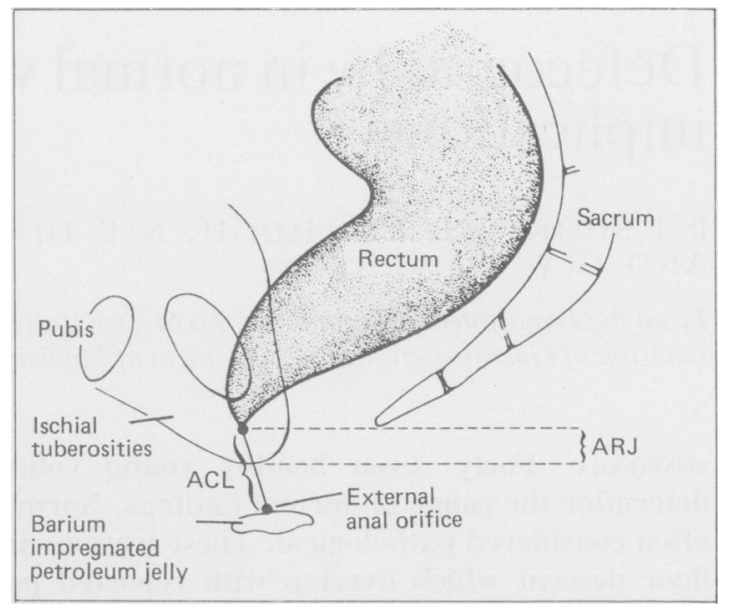

Fig 1 Definitions of measurements of anal canal length $(A C L)$ and anorectal junction $(A R J)$ (see text).

mm films. Both static and derived measurements were performed.

\section{STATIC MEASUREMENTS}

\section{Anal canal length}

This was the distance between the external anal orifice (marked by barium impregnated jelly) and the point at which the parallel straight sides of the anal canal convert to the diverging walls of the distal rectum (Fig. 1).

\section{Anorectal angle}

This was measured by two methods (Fig. 2).

\section{Posterior anorectal angle}

This was represented by the angle between the anal canal and the tangential line drawn along the posterior rectal wall behind the impression just proximal to the upper anal canal.

\section{Central anorectal angle}

This was represented by the angle between the eentre of the rectum and the anal canal. The centre of the rectum was defined as the line bisecting the tangents drawn along the anterior and posterior walls of the distal rectum as illustrated in Figure 2.

\section{Position of anorectal junction}

The site of the upper anal canal (as defined in anal canal length) was measured with reference to the inferior margins of the ischial tuberosities (Fig. 1).

Rectosacral gap

In the resting state the width of the gap between the 


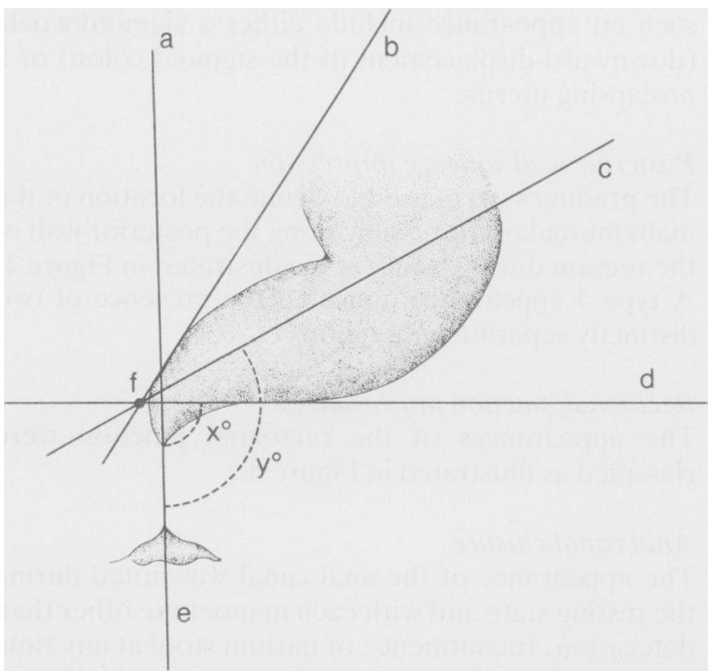

Fig. 2 Illustration of the measurement of posterior anorectal angle (PARA), and central rectal angle (CRA). The PARA is the angle between the axis of the anal canal (line ae) and the tangent to the posterior wall of the rectum (line df). The (RA is the angle between the axis of the anal canal (line ae) and the line of, which bisects the tangents to the distal anterior rectal wall (line bf) and the posterior rectal wall (line $d f$ ).

posterior rectal wall and the sacrum at S3 level was measured directly.

DERIVED MEASUREMENTS

Derived measurements were calculated from two 105 $\mathrm{mm}$ spot films and are illustrated in Figure 2.

\section{Change in anal canal length}

This was determined during both 'squecze' and 'strain' by subtracting the relevant 'squeeze' or 'strain` value from the resting measurement.

\section{Change in posterior anorectal angle and central} anorectal angle

These measurements were again made during 'squecze' and 'strain' with reference to the resting values.

Perineal elevation, descent, and total movement The movement of the anorectal junction during 'squecze' and defecation were calculated as follows: perineal elevation='squecze' value minus resting value: perineal descent $=$ resting value minus defecation value; and, total perineal movement $=$ 'squeeze' value minus defecation value.

\section{Anal canal angulation}

This was derived as the change, from rest to
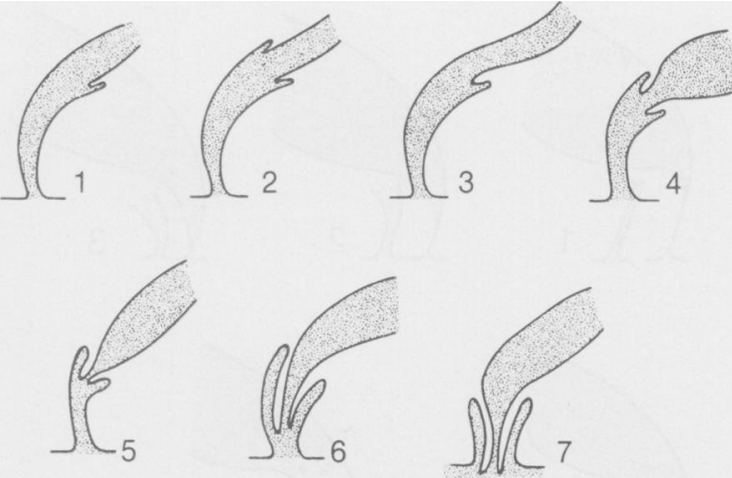

Fig 3 Grading system for mucosal prolapse and intussusception. Grades 1 and 2 represent infoldings in the wall of the rectum of less than $3 \mathrm{~mm}$ in width. Grade 3 is an infolding of $3 \mathrm{~mm}$ or greater but not circumferential. Grade 4 is a circumferential infolding of greater than $3 \mathrm{~mm}$ which remains intrarectal. Grade 5 is similar to Grade 4 but the leading edge of the infolding impinges on the internal anal orifice. In grade 6 the edge is intra anal, and grade 7 it prolapses externally. For illustration sake only, the anal canal has been drawn as if open.

'squeeze', in the angle formed between the longitudinal axis of the anal canal and an arbitrary vertical on the film. A positive result indicated the upper anal canal tipped forward on 'squeeze'.
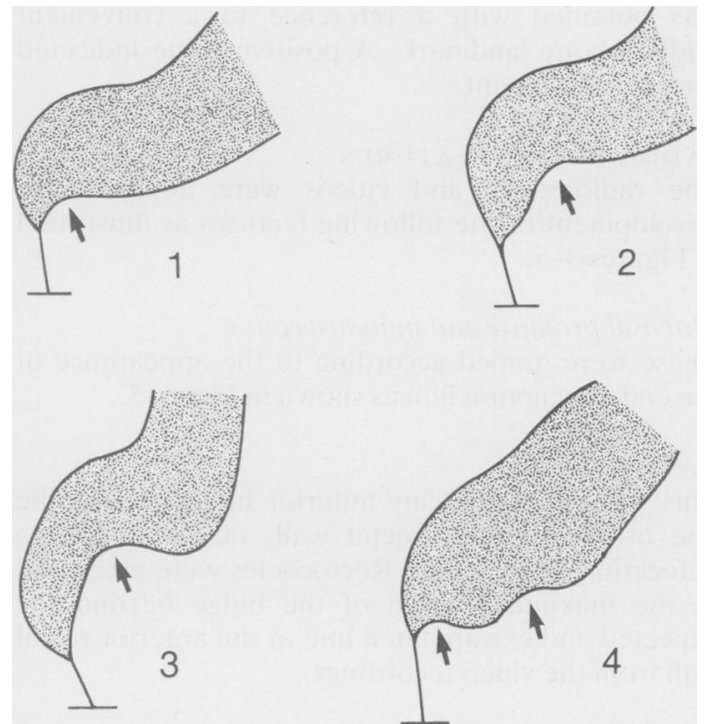

Fig. 4 Types of posterior wall 'squeeze' impression. The posterior wall 'squeeze' impression due to the puborectalis/ levator muscles was divided into four types as indicated (traced from actual defecographic squeeze views). Note type 4 indicates two distinct muscle impressions. 

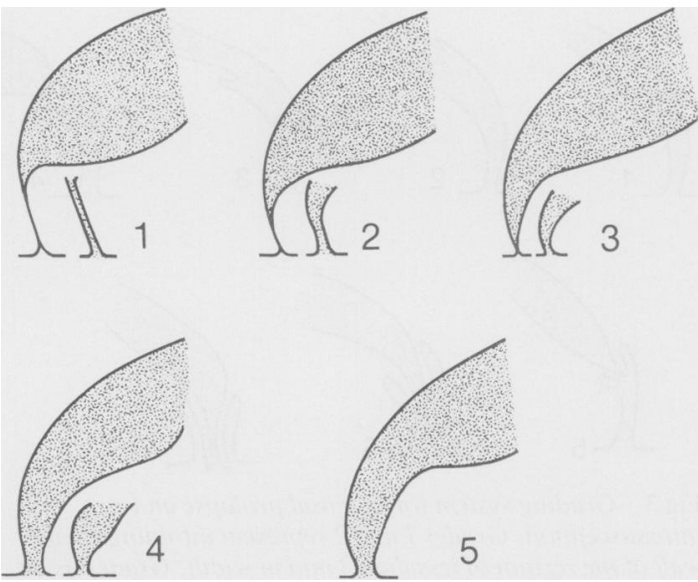

Fig. 5 Grading of anorectal junction appearances. The grading was based on the extent of a cone shaped configuration at the distal rectum/upper anal canal. Grade 1: no significant cone. Grade 2: small cone less than $50 \%$ of the length of the radiographic anal canal. Grade 3: cone greater than $50 \%$ of the length of the radiographic anal canal. Grade 4: the entire anal canal is cone shaped except for a short distal ring like area with parallel walls. Grade 5: Anal canal widely open and not definable as a distinct zone.

\section{Horizontal movement of the anorectal junction}

The horizontal displacement of the anorectal junction between the resting position and 'squeeze' was obtained with a reference to a convenient midline bony landmark. A positive value indicated forward movement.

\section{RADIOGRAPHIC FEATURES}

The radiographs and videos were analysed for development of the following features as illustrated in Figures 3-5.

\section{Mucosal prolapse and intussusception}

These were graded according to the appearance of the end-evacuation film as shown in Figure 3.

\section{Rectocoele}

This was defined as any anterior bulge outside the line of the anterior rectal wall, occurring during defecation or straining. Rectocoeles were measured as the maximum depth of the bulge beyond the expected and extrapolated line of the anterior rectal wall from the video recordings.

\section{Suspected enterocoele}

As small bowel opacification was not used in this study, an enterocoele could only be inferred from a smooth broad indentation of the posterior vaginal and the anterior rectal walls. Other interpretations of such an appearance include either a sigmoidocoele (downward displacement of the sigmoid colon) or a prolapsing uterus.

\section{Posterior wall squeeze impression}

The grading system used to define the location of the main muscular impression along the posterior wall of the rectum during 'squeeze' is illustrated in Figure 4. A type 4 appearance indicated the presence of two distinctly separate impressions.

\section{Rectoanal junction appearances}

The appearances of the rectoanal junction were classified as illustrated in Figure 5.

\section{Anal canal closure}

The appearance of the anal canal was noted during the resting state and with each manoeuvre other than defecation. Incontinence of barium stool at any time was recorded. An open anal canal was subdivided subjectively into either being slightly open or widely open.

\section{Results}

SUBJECTS

Approximately $80 \%$ of the respondents to the advertisement agreed to participate. All of these volunteers completed the study. One man was unable to evacuate any barium paste seemingly because of embarrassment. It was not possible to analyse the films of one female volunteer for technical reasons.

\section{VOLUNTEERS SYMPTOM REPORT}

The mean Likert-type scores on the gastrointestinal symptom inventory showed consistent disagreement with positively worded statements that described the experiencing of symptoms of: diarrhoca; constipation; bowel movements varying between loose and hard; faecal soiling; considerable straining to defecate; urgency to defecate and incomplete rectal emptying - that is, the subjects denied experiencing these symptoms. The voluntecrs reported up to two bowel movements each day and specifically did not use any manouevres to assist with defecation.

ANAL, CANAI. I.ENGTH (Table 1)

The mean resting anal canal length differed $(\mathrm{p}=$ $0.003)$ between men $(\bar{x} 22 \mathrm{~mm})$ and women $(\bar{x} 16$ $\mathrm{mm})$. With "squecze" the anal canal length was increased by greater than $1 \mathrm{~mm}$ in 24 of $25 \mathrm{men}(\overline{\times} 6 \cdot 2$ $\mathrm{mm})$ but in only 16 of 23 women $(\bar{x} 3 \mathrm{~mm})$. The increase in length was significantly greater in men compared with women $(p=0 \cdot 005)$. In the remaining subjects, the anal canal length was essentially unchanged with squeeze efforts. The mean 'squecze' 
Table 1 Direct measurements of anorectal parameters on defecography

\begin{tabular}{|c|c|c|c|}
\hline & Rest & Squeeze & Strain \\
\hline $\begin{array}{l}\text { Anal cana } \\
\text { Men* } \\
\text { Woment }\end{array}$ & $\begin{array}{l}22(7)[10-38] \\
16(5)[6-26]\end{array}$ & $\begin{array}{l}28(9)[12-45] \\
19(6)[6-26]\end{array}$ & $\begin{array}{l}17(6)[9-27] \\
14(5)[6-20]\end{array}$ \\
\hline $\begin{array}{l}\text { Posterior: } \\
\text { Men* } \\
\text { Woment }\end{array}$ & $\begin{array}{l}\text { (A) }\left({ }^{\circ}\right) \\
96(17)[64-125] \\
95(16)[70-134]\end{array}$ & $\begin{array}{l}80(16)[45-116] \\
71(12)[54-95]\end{array}$ & $\begin{array}{r}98(19)[67-123] \\
103(15)[75-128]\end{array}$ \\
\hline $\begin{array}{l}\text { Central an } \\
\text { Men* }\end{array}$ & $\begin{array}{l}\text { A) }\left({ }^{\circ}\right) \\
118(12)[91-140] \\
\text { Rest }\end{array}$ & $\begin{array}{l}113(17)[90-160)] \\
\text { Squeeze }\end{array}$ & $\begin{array}{l}118(12)[97-1.36] \\
\text { Defecate }\end{array}$ \\
\hline $\begin{array}{l}\text { Anorectal } \\
\text { Men* } \\
\text { Woment }\end{array}$ & $\begin{array}{l}\text { JP) }(\mathrm{mm}) \$ \\
16(9)[0-31] \\
4(13)[-32 \text { to }+21]\end{array}$ & $\begin{array}{l}28(9)[9-41] \\
14(12)[-20 \text { to }+28]\end{array}$ & $\begin{array}{l}-4(9) \div[-22 \text { to }+31] \\
16(15)[-48 \text { to }+12]\end{array}$ \\
\hline
\end{tabular}

$* n=25$ except for 'strain' where $n=17 ;+n=22$ except for 'strain' where $n=15$; $\ddagger$ One subject unable to defecate. Mean (SD) [range].

anal canal length was also significantly larger in men $(\bar{x} 28)$ than women $(\bar{x} 19)(\mathrm{p}<0 \cdot 001)$. Straining efforts were assessed in 17 men and 15 women. During 'strain' the anal canal length was shortened in $15(\overline{\times} 7 \mathrm{~mm})$ and unchanged in two men. Similarly, the anal canal length was shortened $(\bar{x} 2 \mathrm{~mm})$ in 11 and unchanged in four women.

POSTERIOR ANORECTAL ANGLE AND CENTRAL.

ANORECTAL ANGLE (Table 1, Fig. 6)

In men, the mean resting posterior anorectal angle was $96^{\circ}$, decreasing to $80^{\circ}$ during 'squeeze', and increasing to $98^{\circ}$ on straining. In women, the respective values were $95^{\circ}, 71^{\circ}$, and $103^{\circ}$. A wide range of values were encountered and there were no significant

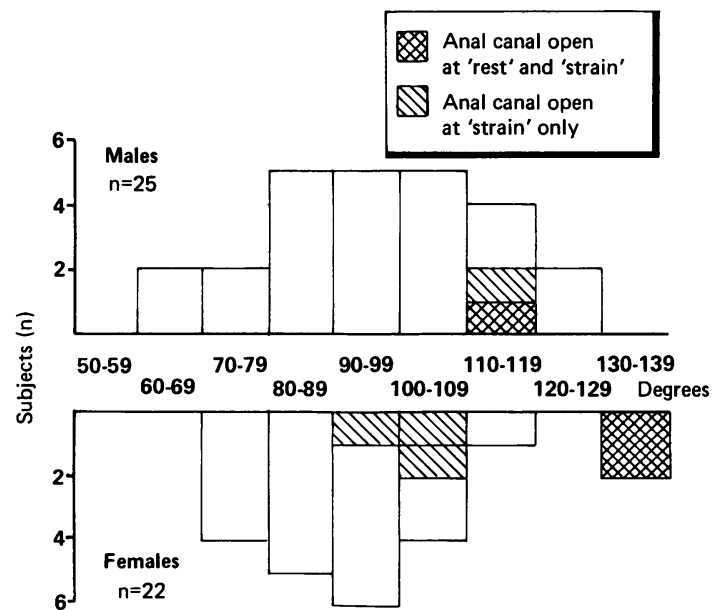

Fig. 6 Histogram indicating variation of PARA at rest in all subjects. Those subjects with an open anal canal are indicated by shading. differences between men and women. During 'squeeze' the posterior anorectal angle was decreased (men, $\bar{x} 16^{\circ}$; women, $\overline{\times} 24^{\circ}$ ) in all but three subjects (one man, two women) in whom there was no change. During 'strain', the posterior anorectal angle increased by $6^{\circ}(\bar{x})$ in men and $4^{\circ}$ in women. In six of 17 men and four of 15 women these values actually decreased. The central anorectal angle could only be accurately measured in men in whom the mean was $118^{\circ}$ at rest. In men, there was less change on 'squeeze' $\left(\overline{\times} 113^{\circ}\right)$ and 'strain' $\left(\bar{x} 118^{\circ}\right)$ for central anorectal angle than the posterior anorectal angle. In 18 subjects central anorectal angle decreased on 'squeeze' but in seven it actually increased.

\section{HORIZONTAL MOVEMENT OF THE ANORECTAL} JUNCTION

During 'squeeze', the anorectal junction moved forward in 17 of $25(68 \%)$ men ( $\overline{\times} 4(2) \mathrm{mm})$ and was unchanged in the remaining eight men. Similarly, 16 of $22(73 \%)$ women showed forward movement ( $\bar{x} 1$ (3) $\mathrm{mm}$ ), four women showed no change and two had backward movement with 'squeeze'.

ANORECTAL JUNCTION Position (Table 1, Fig. 7) For men, the mean anorectal junction position in the resting state was $+16 \mathrm{~mm}$, increasing to $28 \mathrm{~mm}$ during 'squeeze' and decreasing to $-4 \mathrm{~mm}$ during defecation. For women, the anorectal junction position values during these manoeuvres were 4,14 , and $16 \mathrm{~mm}$ respectively and significantly different from men $(\mathrm{p}<0 \cdot 002)$.

PERINEAL FLOOR MOVEMENT (Figs 8-10)

During 'squeeze', the perineal floor was raised in all but one man (men, $\bar{x} 13$ (7) mm; women, $\bar{x} 10$ (7) $\mathrm{mm}$ ). On defecation, the perineal floor descended in 


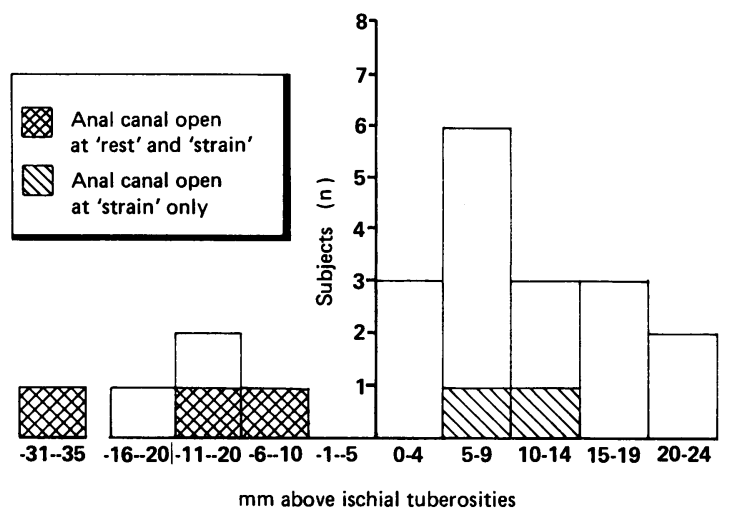

Fig. 7 Histogram indicating the resting portion of the anorectal junction in relation to the caudal margins of the ischial tuberosities in the women. Note that those subjects with open anal canals at rest tended to have low resting positions.

all but one woman (men, $\bar{x} 19(10) \mathrm{mm}$; women, $\bar{x} 20$ (15) $\mathrm{mm}$ ). The range of descent was 2 to $39 \mathrm{~mm}$ in men and 0 to $54 \mathrm{~mm}$ in women. Combining both pelvic floor elevation and descent, the mean total perineal floor movement in men ranged from 18 to 57 $\mathrm{mm}(\overline{\times} 32(10) \mathrm{mm})$ and in women ranged from 7 to $59 \mathrm{~mm}(\overline{\times} 30(12) \mathrm{mm})$. There was no significant difference in these results between men and women.

\section{ANAL CANAL ANGULATION}

During 'squeeze', 15 of 24 (63\%) of men and 13 of 22 $(59 \%)$ women showed forward tilt of the anal canal axis ( $\bar{x}$ anal canal angulation: men, $2^{\circ}\left(6^{\circ}\right)$; women, $4^{\circ}\left(6^{\circ}\right)$. Of the remaining subjects, six men and five women had posterior tilt of the anal canal axis with 'squeeze', and three men and four women showed no change.

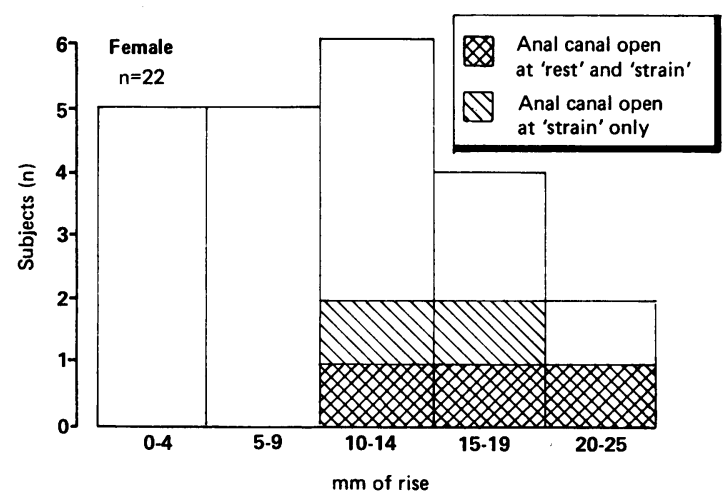

Fig. 8 Histogram depicting the rise of the anorectal junction on 'squeeze'. Note volunteers with open anal canals had better than average lift.

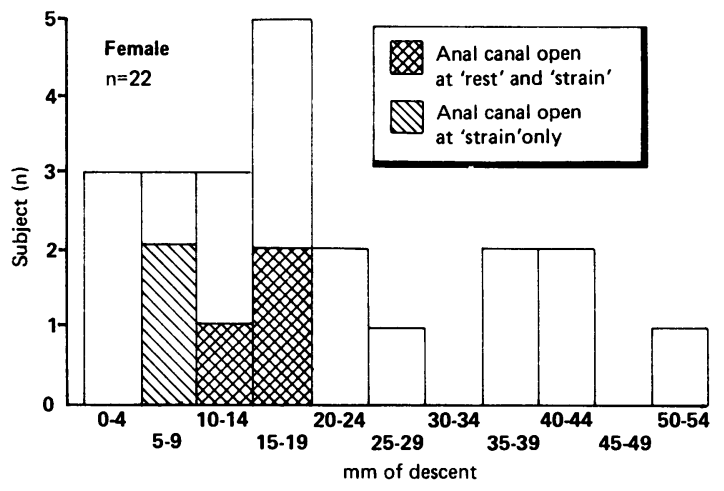

Fig. 9 Histogram indicating the wide variation in descent of the anorectal junction during defecation. Subjects with open anal canals had lower than average descent likely reflecting their low resting positions.

MUCOSAL. PROLAPSE ANDINTUSSUSCEPTION (Table 2)

Mucosal prolapse/intussusception of grade 4 or greater (Fig. 3) was seen in 12 of $24(50 \%)$ men and 10 of $20(50 \%)$ women who emptied their rectum sufficiently for analysis.

Rectocoeles (Table 2, Figs 11-13)

Rectocoeles were much more commonly seen in women ( 17 of 21 or $81 \%$ ) compared with men ( 3 of 24 or $13 \%)$. In 10 of the women (48\% of total) the rectocoeles were $>1 \mathrm{~cm}$ in depth, and in one subject $>2 \mathrm{~cm}$.

ENTEROCOELES (Fig. 12)

In two of the women there was widening of the postvaginal/anterior rectal wall space compatible with an enterocoele (Fig. 13).

POSTERIOR WALL 'SQUEEZE' IMPRESSION In all men and 18 of $22(82 \%)$ women the major

Table 2 Radiographic features

A Mucosal prolapse and intussusception

$\begin{array}{llllllllll}\text { Grade } & \mathrm{n} & 0 & 1 & 2 & 3 & 4 & 5 & 6 & 7\end{array}$

Men $\begin{array}{lllllllll}25^{*} & 5 & 2 & 3 & 2 & 7 & 5 & 0 & 0\end{array}$

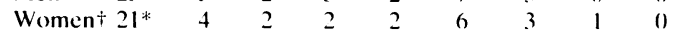

B Rectocoeles (depth) $(\mathrm{cm})$

\begin{tabular}{lccccccc} 
& & $\mathrm{n}$ & $<0 \cdot 5$ & $0 \cdot 5-1 \cdot 0$ & $1 \cdot 1-1 \cdot 5$ & $1 \cdot 51-2 \cdot 0$ & $>2 \cdot 0$ \\
Men & $25^{*}$ & 21 & 21 & 3 & 0 & 0 & 0 \\
Women & $21^{+}$ & 21 & 4 & 7 & 5 & 4 & 1 \\
\hline
\end{tabular}

* One subject had insufficient rectal emptying to evaluate: $†$ One film was not available for analysis. 


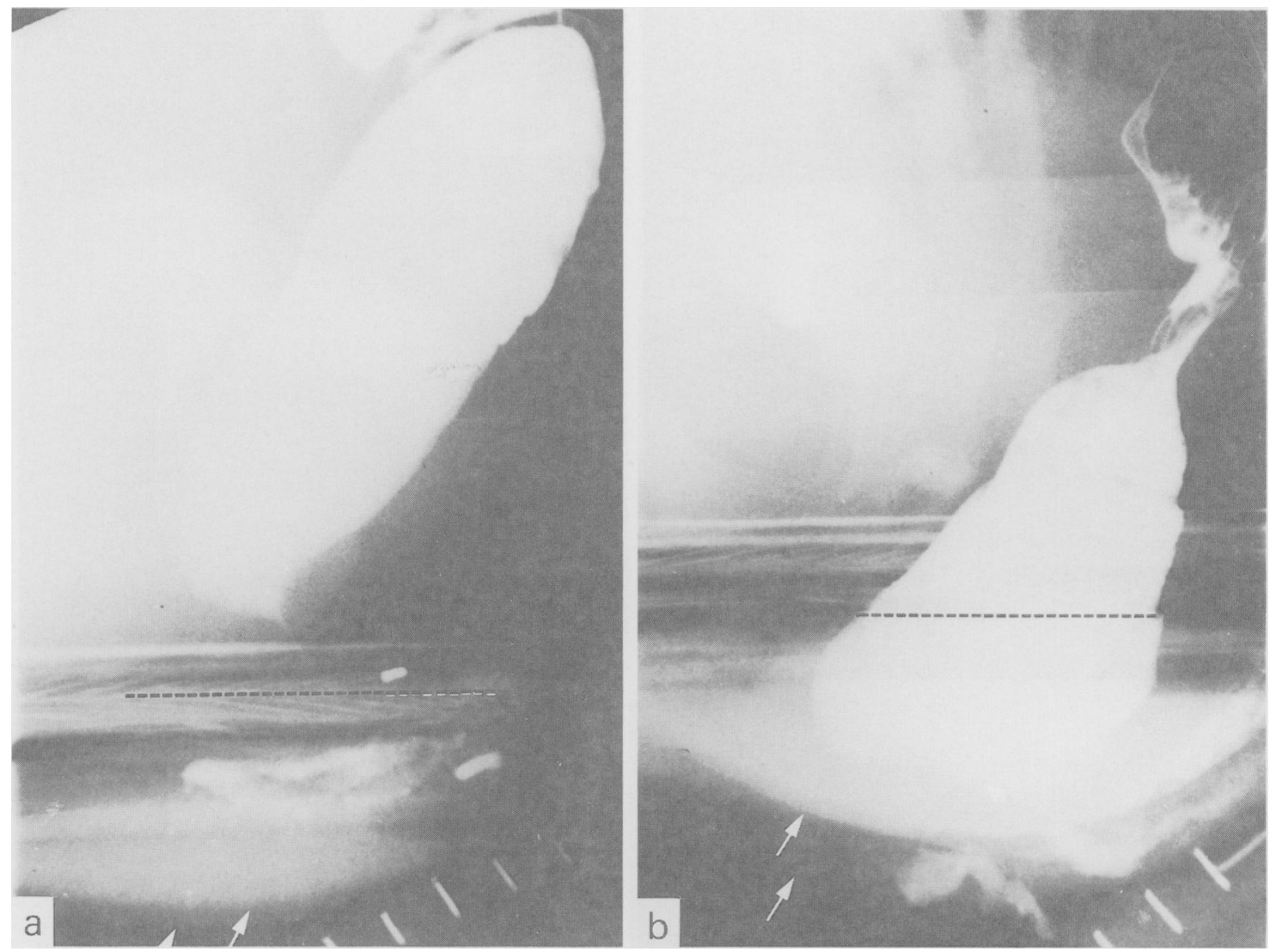

Fig. 10 Defecogram of female subject (no 15). Note: (a) at rest, completely cosed anal canal with grade l anorectal junction appearance; (b) marked descent on attempted defecation, with incomplete rectal emptying. The broken line indicates the level of the inferior aspect of the ischial tuberosities. Arrows=iine produced by external surface of buttocks.

muscle impression and change during 'squeeze' occurred at the location of types 1 and 2 (Fig. 4). In the remaining four women, the major muscle impression was located at a more posterior site (type 3 three subjects and type 4 - one subject) (Fig 12).

RECTOANAL, JUNCTION APPEARANCES

In 24 of $25(96 \%)$ men and 18 of $22(82 \%)$ women the rectoanal junction had little or no proximal cone shape to its appearance during both rest and 'squecze' (grades 1 or 2, Fig. 5). In two women the rectoanal junction was more cone shaped at rest (grade 3 ) but changed during 'squecze' (grade 2). In one man (grade 4) and two women (grade $3=$ one, grade $4=$ one), the rectoanal junction was very cone shaped and did not change whatsoever with 'squecze'.

ANAI. CANAI. CI.OSURE (Figs 6-9)

In the resting state all but one (widely open) of the men had a closed anal canal. In the men, during 'squeeze' one additional subject had an anal canal which became widely open. With straining, a total of four men showed opening of their anal canal (two= widely open; two=slightly open). In the women in the resting state, 20 of $23(87 \%)$ had a closed anal canal and the three other subjects had a widely open canal. During 'squeeze' only one women showed slight anal canal opening. On straining, however, five showed anal canal opening (two=widely open; three $=$ slightly open ).

RECTOSACRAI. GAP

No subject had a rectosacral gap at the S.3 level of greater than $10 \mathrm{~mm}$.

\section{Discussion}

Interest in anorectal and pelvic floor dysfunction as a cause of bowel related symptoms is increasing, but 

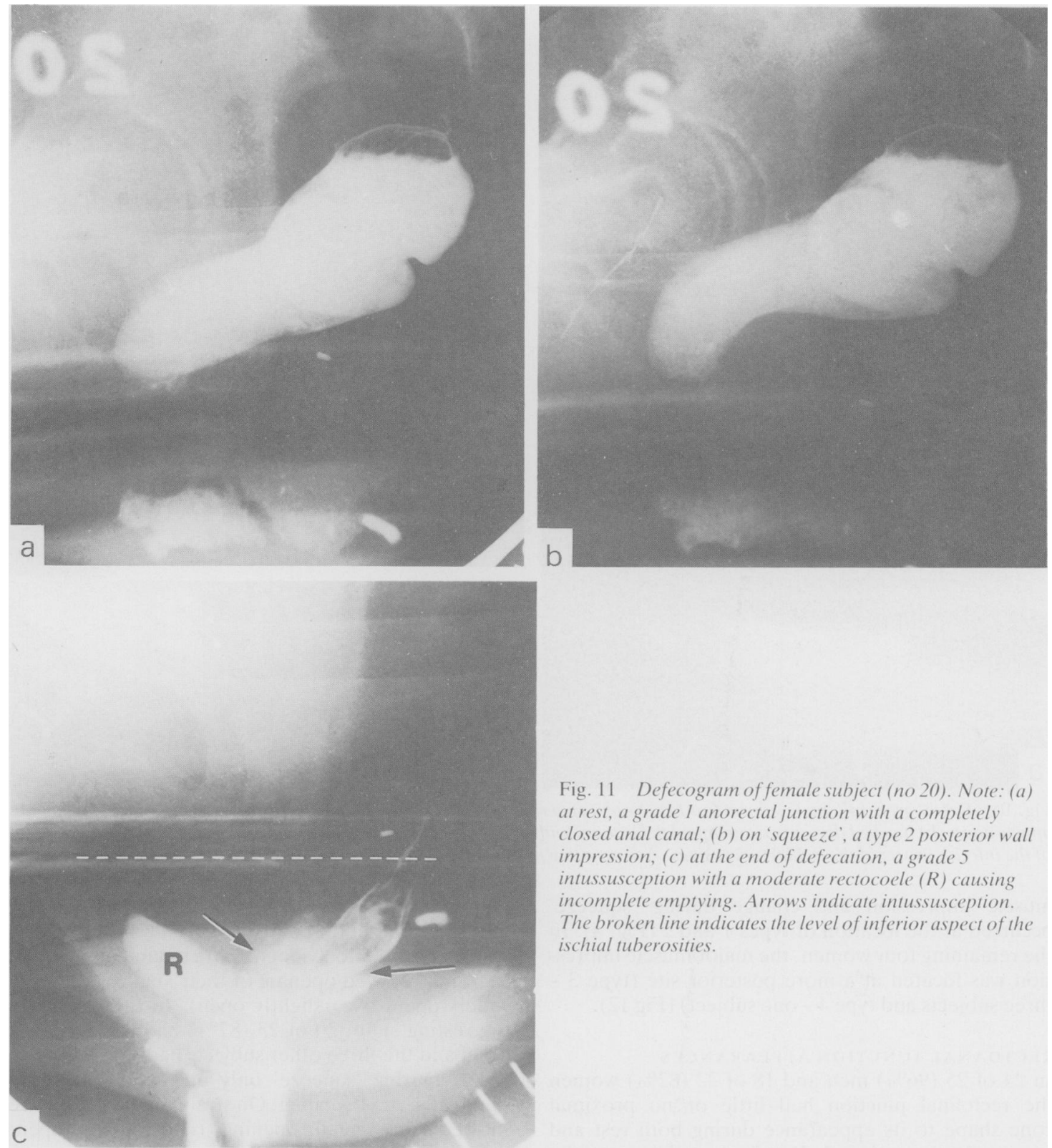

Fig. 11 Defecogram of female subject (no 20). Note: (a) at rest, a grade I anorectal junction with a completely closed anal canal; (b) on 'squeeze', a type 2 posterior wall impression; (c) at the end of defecation, a grade 5 intussusception with a moderate rectocoele $(R)$ causing incomplete emptying. Arrows indicate intussusception. The broken line indicates the level of inferior aspect of the ischial tuberosities.

the pathophysiological mechanisms involved are still poorly understood. Defecography is a minimally invasive investigation which is well tolerated by patients and provides information about anosphincteric, puborectalis and levator muscle, and rectal function as well as rectal pathological anatomy.

Most previous studies on defecography lack standardisation of technique and evaluation. These previous studies have not used controls, ' or have inferred normality retrospectively by defining it as the absence of anatomic pathology (enterocoeles, rectococles and intussusceptions) in their control groups."- Other studies have used control groups taken from a population believed to be normal who 


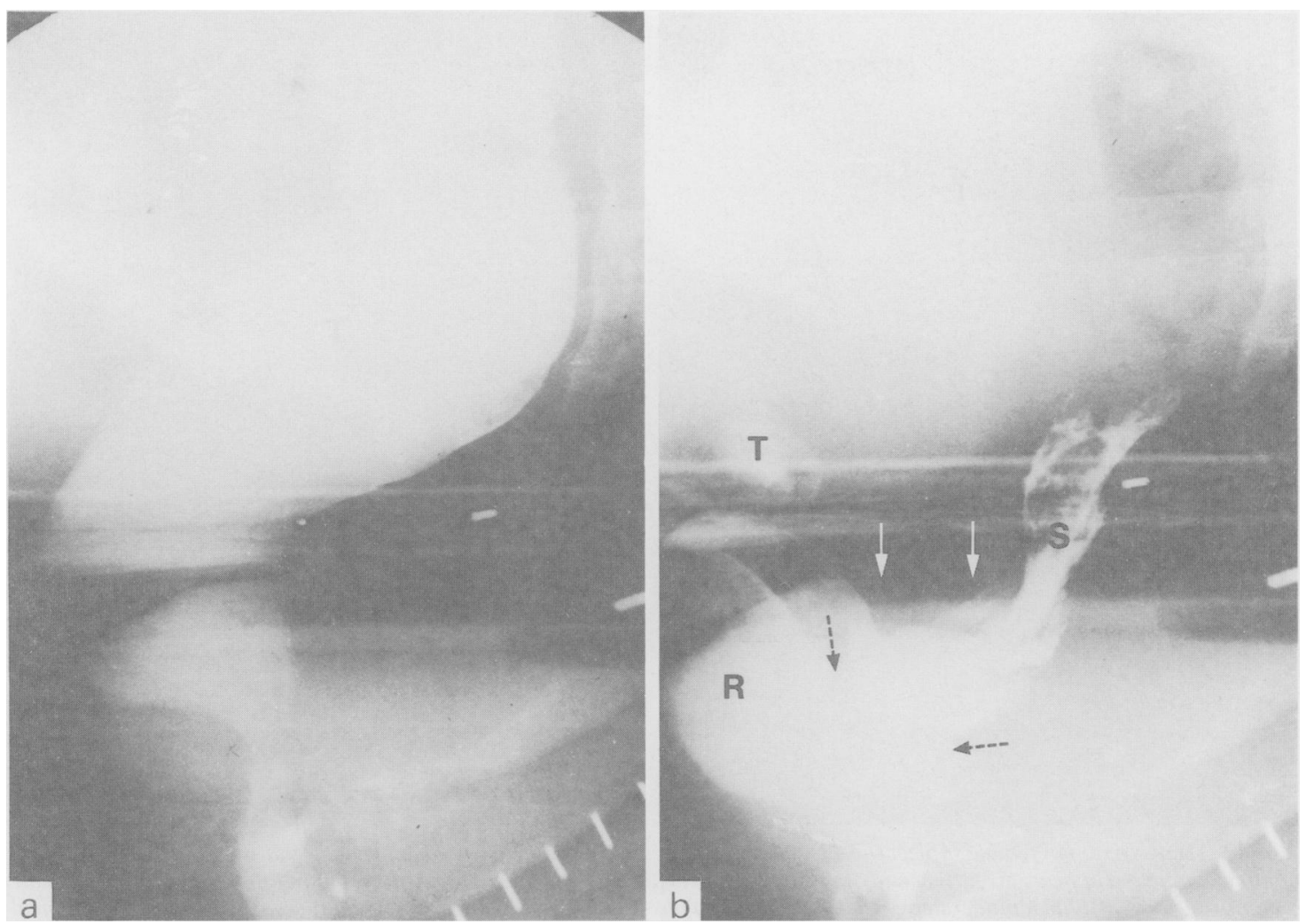

Fig. 12 Defecogram of female subject (no 24). Note: (a) at rest, a grade 3 posterior wall impression (it became more pronounced on 'squeese'), a very short anal canal, grade tanorectal junction appearance, and a low lying pelvic floor; (b) at the end of defecation, a grade o intussusception (broken arrows), small rectocoele $(R)$, and probable enterocoele (solid (arrons).

are undergoing barium enema for a disorder felt not to be anorectal in origin." "I" In particular, detailed findings have been presented by Bartram et al in such subjects, but a selection of study subjects who are having gastrointestinal investigations on the basis of denial of defecatory disturbance does include a possible selection bias. The purpose of the present study was to examine the findings in a healthy population where selection bias was minimised through the manner of recruitment. A few studies have used normal volunteers but detailed findings have not been published. ${ }^{1-1+}$

The manner in which defecography is performed is likely to affect the results. For example, different studies have used techniques using different consistencies of the barium contrast. Liquid in the rectum - that is, diarrhoea, appears to be a potent stimulus of the voluntary muscle component of the continence mechanism. Defecography findings differ if a more liquid contrast stool is used instead of semisolid stool (unpublished observations). That is, there is augmentation of anal canal closure and increased activity in the puborectalis and levator muscles when liquid contrast is used.

Precise definitions of radiographic measurements and evaluations have been lacking, or determined differently. This is well illustrated by considering the measurement of the anorectal angle. The line drawn to indicate the axis of the anal canal is consistent between studies, but the line drawn to indicate the rectal axis is variably ${ }^{3-11}$ or imprecisely defined, producing different numerical values for the same named parameter.

To address these issues, the present study has examined healthy, young, asymptomatic volunteers. Selection bias is unlikely due to the manner of recruitment of the subjects. All the women were nulliparous and therefore, the findings cannot be 


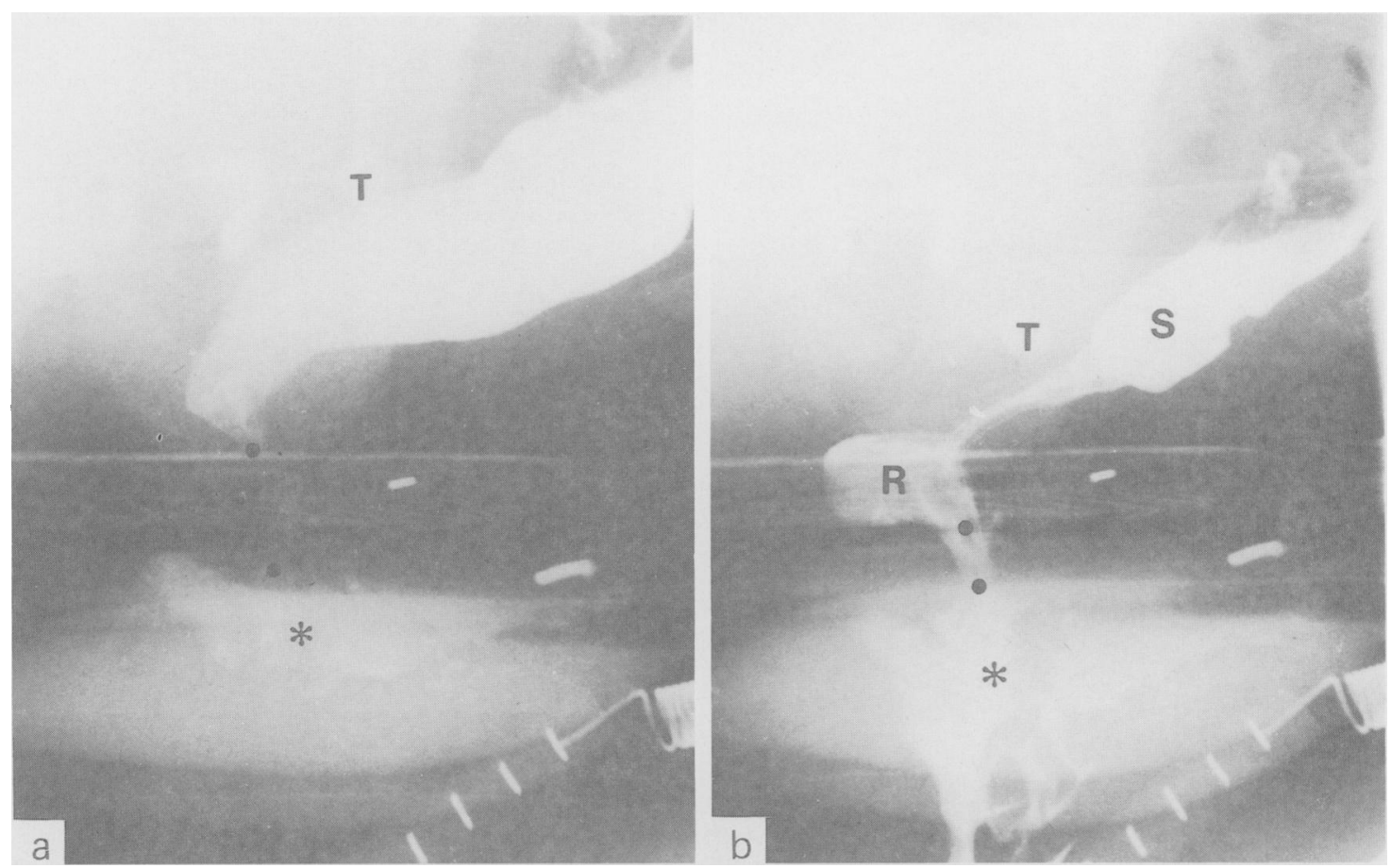

Fig. 13 Defecogram of female subject (no 17). Note: (a) at rest, a completely closed anal canal (indicated by dots), a grade 2 anorectal junction appearance; (b) at end of defecation, no evidence of an enterocoele (the tampon ( $T$ ) is closely applied to the anterior rectal wall), but a moderately sized rectocoele $(R)$ has formed which unlike the rectum, does not empty. ( $*=$ perineal region greased with contrast; $S=$ sigmoid colon).

ascribed to previous childbirth. Siandard definitions for measurements and radiographic features were used.

Men had a longer mean anal canal length than women but the ranges were wide. These lengths determined radiographically are shorter than anal canal length determined manometrically (men, $\overline{\times} 40$ $\mathrm{mm}$; women, $\bar{x} 37 \mathrm{~mm}$ ) as reported by McHugh and Diamant." Part of this variation is probably explained by the method of assessment. At defecography, the anal canal is measured as the distance between the external anal orifice and the point where the cone like distal rectum joins to form parallel walls. The upper portion of the anal canal is often funnel shaped and therefore not included in the radiographic measurements although still likely to be detected as part of the anal canal with anorectal manometry. Also, the length of the manometrically determined anal canal will depend on the diameter of the manometric recording probe used; as larger diameters occlude greater lengths of the cone like proximal canal. Nevertheless, radiographic anal canal closure, length and appearance seem to provide an estimate of the integrity of the high pressure zone, although direct manometric and radiographic correlations have not been reported in the literature.

Eight per cent of the healthy subjects in this study had either an open or partly open anal canal at rest suggestive of low resting anal pressures. On 'squeeze', and presumably with augmentation of the resting anal canal pressures there was lengthening of the anal canal in all but $17 \%$ of subjects. These data parallel the manometric data previously reported where $9 \%$ of normal subjects lack the ability to voluntarily augment the resting anal pressures.'

We considered two methods for measuring the anorectal angle (Fig. 2). The central anorectal angle cannot be accurately defined in women as the gentle curve of the anterior rectal wall prevents any rationale for selecting a suitable tangent. Therefore we agree with Bartram et al that it seems more appropriate to use the posterior anorectal angle based on the use of the posterior rectal wall as this is more easily and reproducibly measured."' We have 
shown that the range of values for the anorectal angle in the 'normal' state is consistent with the values reported by Mahieu et al and Bartram et al in their studies ${ }^{510}$ but is wider than popularly cited. Posterior anorectal angle measurements range up to $125^{\circ}$ for men and $134^{\circ}$ for women. The interpretation of these measurements in patients is questionable as the upper limits of normality overlaps with the values noted during defecation reported by Mahieu $e t a^{56}$ when effacement of the puborectalis is maximal. Contrary to our results Skomorowska and Hegedus have reported a significant sex difference in the resting anorectal angle in a 'normal' population drawn from patients undergoing barium enemas for reasons unassociated with anorectal disease..$^{13}$ The exact method these authors used for measuring the rectal axis is not clear and may account for the differing results. As well, their subjects were also significantly older than in the present study.

Puborectalis muscle function is considered important in the maintenance of continence, although the precise mechanism by which it achieves this effect is controversial. It has been proposed that its action produces a flap ${ }^{1 x}$ or a flutter valve $e^{19}$ although recent studies have questioned these proposed functions." Even though radiographic methods provide a direct visualisation of puborectalis activity, the precise attribution of the radiographic features to the different muscle components of the continence mechanism is not easy. The puborectalis muscle is fashioned like a sling attached to the pubic ramus anteriorly and swings posteriorly behind the anorectal junction. Therefore with voluntary contraction, its action would be expected to pull the anorectal junction anteriorly and superiorly. We have been unable to show, however, either a consistent anterior horizontal movement of the anorectal junction ( $70 \%$ of all subjects) or a forward angulation of the anal canal $(60 \%$ of all subjects) on 'squeeze'. Superficially, these observations appear to belie the proposed mechanism of the puborectalis action. The frequent lack of apparent forward movement or angulation is still, however, compatible with shortening of the puborectalis, if on 'squeeze' the anorectal junction is raised nearer to the pubococcygeal line and the distance from the pubis to the anorectal junction is reduced, but the anorectal junction remains in the same vertical plane. This is difficult to clarify using defecography because the pubis is poorly visualised.

A further variable to consider is the contribution of the puborectalis muscle to proximal anal canal closure. Twenty subjects were graded as having a type 2,3 , or 4 rectoanal junction indicating a more prominent cone-like appearance of the proximal anal canal. This reverted to a lower grade (less prominent cone) on 'squeeze' in nine $(45 \%)$. This change reflecting an increase in the radiological length of the anal canal may be caused by the action of the external sphincter or the puborectalis muscle.

A paradox exists here where it is difficult to collate two functions which appear anatomically disparate. On the one hand, the contribution of the puborectalis to the anorectal junction configuration appears valid. Yet, on the other hand, the muscle is also considered to produce the main muscular impression on the posterior rectal wall which is accentuated on 'squeeze'. Our classification of the puborectalis impression shows a considerable distance between the radiographically defined anorectal junction ( 12 of 25 men and 22 of 22 women were type 2) and the major muscular impression. This muscle has a role in defining the anorectal angle, and its contraction supposedly produces a flap valve. According to this theory, its contraction should appose the anterior and posterior rectal walls. In reality, however, such apposition is never seen on defecographic studies when the rectum is full and presumably the continence mechanisms are stressed. Therefore, we conclude that the muscle impression is actually a composite of the puborectalis and the levator muscles in general, and that each muscle group may make a different contribution in different individuals. The second muscular impression at the anorectal junction can sometimes be discerned and may be more specifically due to the puborectalis.

The anorectal angle consistently decreased on 'squeeze' in our normal volunteers indicating functioning pelvic floor musculature. When the subjects strained down, the anorectal angle generally increased with loss of the posterior rectal impression, but in six of 17 men and four of 15 women the anorectal angle paradoxically increased. Fearing incontinence, the subjects probably contracted the pelvic floor despite contrary instructions. This makes the 'strain' film of limited usefulness and adds unnecessary radiation exposure. Of interest, no subject raised the pelvic floor when straining, indicating that the increase in intraabdominal pressure overcame any tendency to raise the pelvic floor through contraction of the levator muscles. On defecation all subjects showed near complete effacement of the 'puborectalis' impression. The actual anorectal angle then becomes very difficult to measure as the anal canal is widened and shortened such that its central axis is imprecise.

Perineal descent is considered important in many studies, both as a syndrome in its own right ${ }^{1 \times}$ and as part of many other conditions such as rectal prolapse, ${ }^{21}$ obstructed defecation ${ }^{1221}$ and idiopathic faecal incontinence. " 2 Parks and coworkers ${ }^{1 \mathrm{x}}$ introduced the syndrome of 'perineal descent' and 
considered abnormal descent to be present if the anorectal junction was $25 \mathrm{~mm}$ or more below the pubococcygeal line at rest or $30 \mathrm{~mm}$ or more on straining. This line (drawn from the inferior aspect of the pubis to the coccyx) is used in most studies to define the position of the pelvic floor, but is arbitrary and difficult to identify on fluoroscopic video or spot films. To overcome this obstacle, we used instead the level of the inferior margins of the ischial tuberosities which are easy to identify. This same level can be used clinically to measure descent of the pelvic floor." In the resting state, $100 \%$ of men and $77 \%$ of women had an anorectal junction at or above the ischial tuberosities (men, $\bar{x} 16 \mathrm{~mm}$; women, $\bar{x} 4 \mathrm{~mm}$ ). On 'squeeze' virtually all subjects raised the pelvic floor, the average lift being about one centimetre (range 0 to $26 \mathrm{~mm}$ ) in both sexes. The difference in the resting position of the pelvic floor between the sexes may be largely caused by differences in the shape of the bony pelvis which is used as the reference point for measurements.

On defecation there was descent of the pelvic floor in $98 \%$ of subjects. This averaged about $2 \mathrm{~cm}$ in both sexes (maximum descent; men - $39 \mathrm{~mm}$; women - 30 $\mathrm{mm}$ ). Twenty per cent of men and $23 \%$ of women descended more than $30 \mathrm{~mm}$ during defecation. The total movement of the pelvic floor (the difference between the 'squecze' and defecation positions) ranged from 18 to $57 \mathrm{~mm}$ in men and 7 to $59 \mathrm{~mm}$ in women. These data show that radiologically, in the normal defecation position, the pelvic floor is more mobile than is apparent on clinical examination. Therefore, clinical assessment usually performed with patients lying in the lateral position may grossly underestimate perineal descent which becomes maximal only at the onset of defecation, and which is only measurable with defecography. The measurement of descent by defecography is further complicated by the marked shortening of the radiographic anal canal on defecation. That is, the cone of the opened proximal anal canal becomes incorporated into the radiographic distal rectum. These and other factors may account for the greater descent reported by Skomorowska and Hegedus 1. $^{3}$ than was seen in our study.

They noted a mean descent of $45 \mathrm{~mm}$ with a range of 20 to $80 \mathrm{~mm}$. Their study, however, failed to allow for radiographic magnification, and they used the commode for the reference point for measuring descent which does not take into account patient movement on straining.

Our findings showed a subgroup of normal subjects (three women, one man) who had an open anal canal at rest. While they did not report any problems with faecal incontinence, they were visibly incontinent of barium on coughing and straining during defecography. As well, two of these women had the largest resting anorectal angles recorded, and all four subjects tended to be in the upper end of the range (Fig. 6). Furthermore, the women were among the five lowest resting positions of the anorectal junction (Fig. 7), had the shortest anal canal lengths recorded, and yet, all had perineal rise on 'squeeze' in the upper end of the range (Fig. 8). None of these women had remarkable perineal descent on defecation (Fig. 9). It appears that these subjects either manage to avoid incontinence by their above average pelvic floor elevation - that is, excellent puborectalis and levator muscle function, or are continent because they maintain solid stool. It might be argued that the open anal canal is the result of stimulation of the rectoanal inhibitory reflex induced by a full rectum. We feel that this is unlikely as none of these subjects reported any urgency to defecate, and also because the effect was not transitory. It was several minutes after barium paste was inserted that the patients underwent the full defecography procedure and the anal canal remained open throughout this time. In any event, such an explanation would not explain the rest of the parameters indicated above which were at the extreme of their ranges. It is likely that such individuals are at particular risk of incontinence if faced with a diarrhoeal illness or alternatively with trauma to the pelvic floor during child bearing and birth.

Defecography is the only method of investigation of anorectal function that gives anatomical detail such as mucosal prolapse and intussusception. We graded the development of mucosal prolapse and intussusception as a continuum as it was not possible to separate these entities on a defecogram. Grade 4 or higher was felt to be indicative of some degree of circumferential invagination of the full thickness of the rectal wall. It was surprising that about half of both male and female volunteers showed such radiological changes. As intussusception has been considered to be important in the pathogenesis of rectal prolapse, obstructed defecation and the solitary rectal ulcer syndrome, the frequent radiographic findings of mucosal prolapse in the normal control population will have to be taken into account in the interpretation of future studies and emphasises the necessity for appropriate control subjects.

Seventeen of 21 women had either small or moderately sized rectocoeles. Therefore rectocoele formation in women must be considered the norm rather than the exception. These defects in the anterior rectal wall occasionally recoiled at the end of defecation to empty the majority of contrast (two small rectocoeles), but usually the barium appeared to be trapped therein producing incomplete evacuation (15 of 17 rectocoeles seen). Enterococles were uncommon but were suspected in two of 20 women who emptied their rectums sufficiently. 
Defecography also provides dynamic data on the rate and nature of rectal emptying. Assessment of rectal emptying is itself complex, however, and requires more than just subjective description. Even simple measurement of the amount of barium excreted or planimetry of the rectal contour does not take into account barium reflux into the sigmoid colon. The emptying rate may also be dependent on the degree of initial rectal distention and will vary with the consistency of stool or contrast,,$^{, 3}$ and the straining effort of the subject. It is difficult to control for all of these factors, and acknowledging these technical limitations in the present study, we have not directly analysed the efficiency of rectal emptying.

In conclusion, this study has shown a broader range of appearances in normal subjects than previously appreciated. Some of the findings in healthy (normal) subjects may yet, in individual patients, combine with other variables to have functional and clinical significance. For example, a fibre deficient diet in a subject passing scybalous stool who also has an intussusception, may combine to produce anorectal symptoms which are 'curable' with dietary change. ${ }^{33}$ Whether similar scenarios contribute to the development of pathological states - for example, prolapse, or clinical syndromes such as descending perineum, is speculative at present. It would appear that radiological investigation of defecation while still in a state of infancy, has much to offer for our understanding of both normal function and pathological states. Active collaboration between clinicians and radiologists is important to obtain the maximum clinical benefit from studying individual subjects using defecography.

This research was funded by the Elsie Watt Fund, Toronto Western Hospital. The authors appreciate the assistance of $\mathrm{Dr} A$ Rainbow, Department of Medical Physics, McMaster University; and $\mathrm{Mr} \mathrm{S}$ Lico, Toronto Western Hospital. This paper has been presented in part at the British Society of Gastroenterology, London, September, 1987 and the Radiological Society of North America, Chicago, October 1987.

\section{References}

1 Burhenne HJ. Intestinal evacuation study: a new roentgenologic technique. Radiol Clin 1964: 33: 79-84.

2 Brown BStJ. Defecography or anorectal studies in children including cincfluorographic observation. J Can Assoc Radiol 1965: 16: 66-76.

3 Broden B. Snellman B. Procidentia of the rectum studied with cineradiography: contribution to the discussion of causative mechanism. Dis Colon Rectum 1968: 11: 330-47.
4 Edwards DAW. Beck ER. Movement of radiopacified feces during defaccation. Am J Dig Dis 1971: 16: 7(0911.

5 Mahicu P. Pringot J. Bodart P. Defecography: I. Description of a new procedure and results in normal patients. Gastrointest Radiol 1984; 9: 247-51.

6 Mahicu P, Pringot J. Bodart P. Defecography: II. Contribution to the diagnosis of defecation disorders. Gastrointest Radiol 1984; 9: 253-61.

7 Ekberg O. Nylander G, Fork FT. Defecography. Radiology 1985; 155: 45-8.

8 Bernier P. Stevenson GW, Shorvon PJ. Defaccography commode. Radiology 1988; 166: 891-2.

9 Roe AM. Bartolo DCC. Mortensen NJ. Techniques in evacuation proctography in the diagnosis of intractable constipation and related disorders. J Roy Soc Med 1986; 79: $331-3$.

10 Bartram CL. Turnbull GK, Lennard-Jones JE. Evacuation proctography: An investigation of rectal expulsion in 20 subjects without defecatory disturbance. Gastrointest Radiol 1988; 13: 72-80.

11 Bartolo DCC, Read NW, Jarratt JA, Read MG, Donnelly TC, Johnson AG. Differences in anal sphincter function and clinical presentation in patients with pelvic floor descent. Gastroenterology 1983; 85: 6875 .

12 Bartolo DCC, Roe AM, Virjee J, Mortensen NJ. Evacuation proctography in obstructed defaccation and rectal intussusception. Br J Surg 1985; 72 [suppl]: S111-6.

13 Skomorowska E, Hegedus V. Sex differences in anorectal angle and perineal descent. Gastrointest Radiol 1987; 12: 353-5.

14 Womack NR. Williams NS, Holmficld JHM, Morrison JFB. Pressure and prolapse - the cause of solitary rectal ulceration syndrome. (jut 1987; 28: 1228-33.

15 Preston DM, Lennard-Jones JE. Thomas BM. The balloon proctogram. Br J Surg 1984; 71: 29-32.

16 McHugh SM. Diamant NE. Anal canal pressure profile: A reappraisal as determined by rapid pullthrough technique. (Gut 1987; 28: 1234-42.

17 McHugh SM, Diamant NE. Effect of age, gender and parity on anal canal pressures. Contribution of impaired anal sphincter function to faccal incontinence. Dig Dis Sci 1987: 32: 726-36.

18 Parks AG. Porter NH, Hardcastle J. The syndrome of the descending perineum. Proc Roy Soc Med 1966; 59: 477-82.

19 Phillips SF, Edwards DAW. Some aspects of anal continence and defaccation. Gut 1965: 6: 396-405.

20) Wassef R, Rottenberger DA, Goldberg SM. Rectal prolapse. Curr Probl Surg 1986; 23: 402-51.

21 Womack NR, Williams NS. Holmficld JHM. Morrison JFB. Simpkins KC. New method for the dynamic assessment of anorectal function in constipation. Br J Surg 1985; 72: 994-8.

22 Henry MM, Parks AG, Swash M. The pelvic floor musculature in the descending perineum syndrome. Br J Surg 1982: 69: 47()-2.

23 Bannister JJ. Davison P. Timms JM, Gibbons C, Read NW. Effect of stool size and consistency on defecation. Gut 1987; 28: 1246-50. 